\title{
Analysis of the Effect of Hospital Resources on Patients in Indonesian Hospitals
}

\author{
https://doi.org/10.3991/ijoe.v15i10.10870
}

\author{
Yuli Eni ${ }^{(凶)}$, Edi Abdurachman, Asnan Furinto, Dezie Warganegara \\ Bina Nusantara University, Jakarta, Indonesia \\ yulieni.leni@gmail.com
}

\begin{abstract}
Health is the most important thing in human life. Humans can sacrifice anything for health. Health needs to be supported by government facilities, one of which is a hospital. The development of hospitals in Indonesia is increasingly rapid. The availability of more hospitals needs to be supported by the resources available in the hospital. The problem that occurs at this time is that there are still many patients who complain about the lack of availability of resources both in terms of doctors, beds that must be included in the waiting schedule, medical technicians who sometimes queue up for blood collection, administrative processes that take a long time so patients are not immediately treated so on. Therefore, this study was conducted to examine the influence of resources (building area, general practitioners, specialist doctors, nurses, pharmacists, medical technicians, health workers, and non-health workers) on patients (outpatient, inpatient, and emergency room) ) in Indonesian hospitals. The method used is multiple regression with the help of SPSS 20. While the data taken is the population of all hospitals in Indonesia. The results obtained are three, first, building area, bed and medical conditions affect inpatient. Both general practitioners, medical technicians, health workers and non-health workers influence outpatients. Finally, beds, general practitioners, medical specialists, medical technicians, and health workers influence ED patients. Based on the results of these studies it can be suggested that the main focus for each type of patient needs to be considered especially those that have a significant effect.
\end{abstract}

Keywords—-Resources, Patients, Regression, Hospital

\section{Introduction}

Health is an overall condition that includes the physical, mental and social aspects of each individual human being [1]. The health industry is one indicator that supports economic progress and prosperity. In addition, the health industry is also one of the government's priorities because it is related to the quality of human resources. Health is the right of all Indonesian people, and the people of Indonesia are entitled to proper health facilities. One facility that supports health is the role of hospital growth [2]. The growth in the number of hospitals is considered important to meet people's needs. Government efforts to support this hospital are carried out to provide health services that can be used by the community. The rate of increase in the average per year of the 
hospital is $4.9 \%$. If seen from 2013 and 2017 the average number of increase in the number of hospitals reached $5.31 \%$. In line with the growth of hospitals, the need for resources in hospitals has also increased. Resources to support hospitals include doctors, beds, pharmacists, nurses, pharmacies, medical technicians, health workers, and non-health workers. The average increase in the number of doctors per year reached $6.72 \%$. If it is associated with the growth in the number of hospitals, the growth in the number of doctors is still higher than the growth in the number of hospitals which is $5.31 \%$. The difference in increase also indicates the existence of inefficient hospital conditions.

\section{$2 \quad$ Literature Review}

Regression analysis is a mathematical model that can be used to determine the pattern of relationships between two or more variables. Regression analysis uses the basic concepts of correlation but provides more information by showing a linear relationship between two variables in the form of equations [3].

Regression equation (regression equation) is a mathematical equation that defines the relationship between two variables. Using these equations, researchers can estimate the value of the dependent variable based on the value chosen from the independent variable. Variables whose value will affect the value of other variables are called independent variables, while variables whose values are influenced by the value of other variables are called dependent variables.

Regression analysis is more accurate in conducting correlation analysis, because in the analysis it is difficult to show the degree of change in a variable to other variables. So with regression analysis, forecasting or estimating the value of the dependent variable on the value of the independent variable is more accurate. Because it is a prediction, the predictive value is not always right with the real value, the smaller the level of deviation between the predicted value and the real value, the more precise the regression equation is formed.

\section{$3 \quad$ Methodology / Materials}

This research uses quantitative methods. Quantitative methods are research methods that are based on positivist philosophy, sampling techniques are generally carried out randomly, data collection uses research instruments, data analysis with the aim of testing the hypotheses that have been determined.

The data used is hospital data obtained from the health ministry page data of the Republic of Indonesia. Time data collection (Time horizon) for the related variable is One Shot Cross-Sectional, which is a study conducted by data taken only once in a given period, to answer research questions or research hypotheses.

The population categories included in this study are types of hospitals which include general hospitals and special hospitals. Categories of ownership include private and public. The accreditation category covers the prime, graduating basic, middle, 
primary, plenary. Finally for the category of regions divided into class A (Center), B (Province), and C (District).

\section{$4 \quad$ Results and Findings}

The estimation and testing of the Cobb-Douglas production function is the result of processing data between input and output variables that are already in Ln according to the following cobb-Douglas function.

$\ln \mathrm{Yi}=\beta 0+\beta 1 \ln \mathrm{X} 1, \mathrm{i}+\beta 2 \ln \mathrm{X} 2, \mathrm{i}+\beta 3 \ln \mathrm{X} 3, \mathrm{i}+\beta 4 \ln \mathrm{X} 4, \mathrm{i}+\beta 5 \ln \mathrm{X} 5, \mathrm{i}+\beta 6 \ln$ $X 6, I+\beta 7 \ln X 7, I+\beta 8 \ln X 8, I+\beta 9 \ln X 9, I$

Table 1. Variables and values based on cobb-Douglas function

\begin{tabular}{|c|c|c|}
\hline Dependent Variable & Independent Variable & Significant Value \\
\hline \multirow{9}{*}{ 1. In Inpatients } & Ln Building area & 0.115 \\
\hline & Ln Bed & $0.000 * * *$ \\
\hline & Ln General practitioners & 0.171 \\
\hline & Ln Medical specialist & $0.087 *$ \\
\hline & Ln Nurse & $0.010 * * *$ \\
\hline & Ln Pharmacist & 0.713 \\
\hline & Ln Medical Technique & $0.005 * * *$ \\
\hline & Ln Health workers & 0.787 \\
\hline & Ln Non-Health Workers & $0.052 *$ \\
\hline \multirow{9}{*}{ 2. Ln Outpatient } & Ln Building area & $0.075^{*}$ \\
\hline & Ln Bed & $0.059 *$ \\
\hline & Ln General practitioners & $0.011 * *$ \\
\hline & Ln Medical specialist & 0.168 \\
\hline & Ln Nurse & 0.188 \\
\hline & Ln Pharmacist & 0.643 \\
\hline & Ln Medical Technique & $0.000 * * *$ \\
\hline & Ln Health workers & 0.232 \\
\hline & Ln Non-Health Workers & $0.046 * *$ \\
\hline \multirow{9}{*}{$\begin{array}{l}\text { 3. Ln Emergency Installation } \\
\text { patient }\end{array}$} & Ln Building area & 0.13 \\
\hline & Ln Bed & 0.17 \\
\hline & Ln General practitioners & $0.036 * *$ \\
\hline & Ln Medical specialist & 0.827 \\
\hline & Ln Nurse & $0.025 * *$ \\
\hline & Ln Pharmacist & 0.502 \\
\hline & Ln Medical Technique & $0.000 * * *$ \\
\hline & Ln Health workers & 0.271 \\
\hline & Ln Non-Health Workers & $0.021 * *$ \\
\hline
\end{tabular}

*) Signifikan Level $10 \%=0,10$

**) Signifikan Level 5\%=0,05

$* * *)$ Signifikan Level $1 \%=0,01$

The results of significance are the results of the influence between the dependent variable and the independent variable. The results in the table above are divided into 3, namely: 


\subsection{Inpatients}

Beds, nurses and medical technicians have a value of less than 0.05 , it can be concluded that there is a significant influence between beds, nurses and medical technicality on the number of inpatients.

Whereas for specialists and non-health workers it has a value of less than 0.10 , this indicates that with an error rate of $10 \%$, there is a significant influence between specialist doctors and non-health workers with inpatients.

Based on the results of the decision, it can be concluded that if a patient is an inpatient, the variable that affects the patient's interest in the hospital is from the number of beds that are sufficient so that the patient does not have to wait too long to get a bed to stay. The second thing that needs to be considered is the specialist who handles the inpatients so that the patient can be treated quickly by specialist doctors. Third, the number of nurses must also support because inpatients need nurses to control at the right time. Finally, medical technics and non-health workers must also be complete to handle inpatients.

\subsection{Outpatient}

Variables of Building Area, Bed, General Practitioner, Medical Technique, NonHealth Workers have a value less than the assumed level of error in this study which is $5 \%$ and $10 \%$ so that there is a significant influence between Variable Area of Buildings, Beds, General Practitioners, Medical Technique, Non-Health Workers with outpatients.

Based on the results obtained, it can be concluded that an outpatient can see that the hospital is large or not, then the availability of beds, general practitioners, and medical technics can be a decision factor for the selection of hospitals by outpatients. Then the last is a non-medical technique where outpatients need this energy to quickly and accurately complete the administration of the payment process.

\subsection{Emergency installation patient}

General practitioners, nurses, medical technicians, non-health workers have a significant influence on ED patients.

Usually for ED patients, things that need to be considered are the availability of general practitioners, nurses and medical technicians who are always available during emergencies. So that patients feel quickly handled in emergency conditions. In addition, non-health workers also have an influence on ED patients, this shows that ED patients need an administrative process so that doctors take action more quickly while in an emergency.

\section{Conclusion}

Each patient has a different service focus for each patient, outpatient, and patient emergency. This can be seen from the results of the significance of each variable. If a 
patient is an inpatient, then the variable that affects the patient's interest in the hospital is from the number of beds that are sufficient so that the patient does not have to wait too long to get a bed to stay. The second thing that needs to be considered is the specialist who handles the inpatients so that the patient can be treated quickly by specialist doctors. Third, the number of nurses must also support because inpatients need nurses to control at the right time. Finally, medical technics and non-health workers must also be complete to handle inpatients.

If an outpatient can see that the hospital is large or not, then the availability of beds, general practitioners, and medical techniques can be a decision factor for the selection of hospitals by outpatients. Then the last is a non-medical technique where outpatients need this energy to quickly and accurately complete the administration of the payment process.

Especially for ED patients, things that need to be considered are the availability of general practitioners, nurses and medical technicians who are always available during emergencies. So that patients feel quickly handled in emergency conditions. In addition, non-health workers also have an influence on ED patients, this shows that ED patients need an administrative process so that doctors take action more quickly while in an emergency.

\section{$6 \quad$ References}

[1] Hn, S. (2015, 12 17). Peranan Sektor Kesehatan dalam Pembangunan. Retrieved from www.ajarekonomi.com: https://www.ajarekonomi.com/2015/12/kesehatan-sebagai-inves tasi-pembangunan.html

[2] Syukro, R. (2017, 12 11). Ekonomi. Retrieved from Pendidikan dan Kesehatan Kunci Pertumbuhan Ekonomi: https://www.beritasatu.com/ekonomi/467939/pendidikan-dankesehatan-kunci-pertumbuhan-ekonomi. https://doi.org/10.18196/jesp.19.1.2727

[3] Lind, D. A., Marchal, W. G., \& Wathen, S. A. (2018). Statistical Techniques in Business \& Economics (Seventeenth Edition). New York: McGraw-Hill Education.

\section{$7 \quad$ Authors}

Yuli Eni is a researcher in the department of management, at the BS Undergraduate Program, Bina Nusantara university. Mail : yulieni.leni@gmail.com

Edi Abdurachman works for Binus Business School Doctor of Research in Management.

Asnan Furinto works for Binus Business School Doctor of Research in Management.

Dezie Warganegara works for Binus Business School Doctor of Research in Management.

Article submitted 2019-02-14. Resubmitted 2019-04-05. Final acceptance 2019-05-15. Final version published as submitted by the authors. 